\title{
Analysis on Relationship between Tourism Aesthetics and Development and Utilization of Tourism Resources
}

\author{
Linman Li \\ Chongqing University of Education, Chongqing, 400067, China
}

Keywords: Tourism aesthetics, Tourism resources, Development and utilization, Relationship.

\begin{abstract}
Aesthetics is an important content in tourism. The object of tourism aesthetics is mainly tourism resources. With the development of tourism industry and tourism aesthetics, tourism aesthetics has produced certain influence on tourism industry in each region. It has great influence on the concept of development and utilization of tourism resources. This paper mainly analyzes the relationship between tourism aesthetics and development and utilization of tourism resources.
\end{abstract}

\section{Introduction}

Tourism is a kind of social practice. There were records about tourism in ancient China, e.g. journey of King Mu of Zhou to the west. Since the reform and opening up, living quality and standard of people have been both improved. Tourism becomes a main way for people to relax and relieve pressure. Large, medium and small cities in China define themselves as tourism cities. In other words, they regard tourism as their leading industry. However, many problems occur in the process of rapid development of tourism industry. Most cities have not found an aesthetic orientation suitable for themselves. Therefore, they have used tourism construction mode inappropriate for them successively, thus causing great waste of their tourism resources.

\section{Meaning of tourism aesthetics}

The main purpose of tourism is sightseeing. It is an activity of leaving the original place of residence and visiting a strange place for temporary stay by means of travel. Four elements of tourism range from tourism resources, tourists, tourism industry and tourism activities to paper publishing. Aesthetics is under aesthetic category. It mainly refers to mutual interchange of aesthetic subject and its object through aesthetic medium. Currently, aesthetics has become a main activity purpose of tourism. Aesthetics and tourism combine with each other and become tourism aesthetics. Aesthetics is an intention of tourist activities. Tourism is a way for tourists to meet their aesthetic demands. Therefore, modern tourism has significant aesthetic features. Tourism aesthetics has basic features of aesthetics. However, basic features of aesthetics change in connotation and extension due to particularity of tourism. In terms of aesthetic connotation, tourism aesthetics mainly refers to tourists' personal experience, appreciation and creation of beauty in the process of travel. Tourism aesthetics is not static aesthetics. It includes dynamic aesthetics such as experience and participation.

\section{Aesthetic factors of tourism resources}

Feeling: feeling is a feature of objective things. The brain will make a corresponding response through activities of sensory organs such as eyes, ears and nose. It is a simple psychological change process. There are mainly two preconditions for the formation of aesthetic feeling through sensory organs: first, the feeling produced by people is aesthetic feeling; second, the objective world is the precondition of aesthetic feeling of people. The process of changing feeling into aesthetic feeling is from tourism resources to sensory organ to aesthetic feelings.

Consciousness: it is a psychological process of people due to the connection between the surface and overall image of objective things. It is mainly obtained through integration, analysis and 
association of feeling. Compared to feeling, consciousness is more complete and complicated. It is a product of combination of multiple feelings.

Thinking: thinking is a cognitive process of integration, analysis, judgment and reasoning of things through concept and presentation. It includes imagery thinking and logical thinking. Tourists have imagination and understandings of objective things through feeling, consciousness and thinking. Therefore, tourists can have a deep impression on tourism resources and obtain more aesthetic feelings in the process of travel through more imagination and understandings.

Emotion: emotion is a subjective behavior of people towards things. Corresponding physiological changes and external behavioral expression accompany emotion. Emotion is temporary and situational.

Sentiment: sentiment is complicated and senior experience. Sentiment has certain relation with social demands and opinions and position of individuals. It is profound and stable.

Difference between emotion and sentiment: sentiment is stable and profound and emotion is temporary and situational.

Relationship between sentiment and emotion: both of them are expressed as pleasure, anger, sorrow and joy.

\section{Aesthetic feeling of tourism resources}

People have many objectives and motivations of tourism. The objective and motivation of each tourism of the same person change certainly. Pursuit for beauty is contained in tourism activities no matter who he is and what his objective and motivation of tourism are. The enjoyment of beauty is the priority. The ultimate aim of tourism is to feel and enjoy beauty. Tourism operating personnel and employees should not just consider the number of tourists received and economic benefit obtained in a scenic spot. Presenting beauty in tourism resources to tourists and possessing the ability of creating and discovering beauty are key points of tourism management.

Image beauty: the image of tourism resources mainly refers to the combined beauty of form and space form of heaven and earth. Image beauty can be generally summarized as wonder, magnificence, steepness, peace and openness etc.

Color beauty: tourism resources have rich colors, mainly including flowers and trees, rosy clouds, rivers, lakes and seas, sunshine and air, which give tourists a feast for eyes. Color can be generally summarized as the color of mountain, water, sky, stone and plant etc.

Beauty of coordination: beauty of state coordination. Such beauty of coordination mainly refers to artificial satisfaction of demands for aesthetics and art processing of natural environment, e.g. construction of pavilions, terraces and open halls, so as to integrate tourism resources and improve harmony. Beauty of psychological coordination mainly allows tourists to associate morality, sentiment and noble character in fairy tales, historical figures, celebrity stories and classic legends through sceneries and obtain psychological enjoyment of beauty so as to improve the appeal of tourism resources to tourists.

Beauty of custom: it generally includes mystery, uniqueness, experience and authenticity.

\section{Aesthetic methods of tourism resources}

Fixed point - scattered point method; fixed-point perspective method - static viewing method: while enjoying tourism resources, tourists can find an aesthetic perspective accurately and enjoy tourism resources from this perspective. Separated appreciation method: in the process of aesthetics of tourism resources, an object is dissociated from the real background and such resources are appreciated as a closed system so as to achieve higher satisfaction. Association - imagination method: such method belongs to high-level aesthetics. It can allow tourists to enjoy living aesthetics and the sense of beauty deeply in the process of travel. Method of appreciation with association: such method regards tourism resources as a perceptual charm to touch tourists, arouse their aesthetic experience and make them have new aesthetic objects of tourism resources. Method of appreciation with imagination: this method can make tourists' perception act on tourism resources directly and 
allow tourists to create a new aesthetic image in the brain. Scene integration method: this method involves high-quality appreciation of tourism resources and can make tourists enchanted. Method of recalling old memories at familiar sights: it triggers various emotional responses of tourists in the process of appreciation and aesthetics of tourism resources. Scene selection based on emotion: tourists select tourism resources that can meet their emotional needs and pin their inner emotion on external tourism resources.

\section{Relationship between Tourism Aesthetics and Development and Utilization of Tourism Resources}

Tourism industry can generally be divided into tourism resource development and tourism activities. Tourism aesthetics in the narrow sense is only limited to study on tourism activity process. Tourism aesthetics in the broad sense is study on tourism aesthetics in tourism industry. Two processes of tourism industry have different subjects and objectives. Aesthetics in the narrow sense mainly refers to the evaluation and appreciation of tourism projects by tourism experts and staffs so as to conduct tourism design and planning and produce tourism products. Aesthetics in the broad sense refers to appreciation and experience of tourism products by tourists so as to make tourists produce a sense of beauty. Logical relationship of resource development, tourism resource appreciation and experience of tourism activities exists between tourism industry and modern tourism. Second-degree aesthetics exists in this logical relationship. Therefore, the main problem to be solved in the development process of tourism resources is how to coordinate second-degree aesthetics. Though first-degree aesthetics plays a certain role in the development of tourism resources and tourism industry, with the development of tourism industry and the improvement of tourists' quality, tourism industry has gradually transferred from seller to buyer and the influence of second-degree aesthetics on the development and utilization of tourism resources has gradually increased.

\section{Thinking on utilization of tourism resources from tourism aesthetics}

\section{Thinking on scope of development and utilization of tourism resources}

Tourism is a dynamic aesthetic activity which has strong comprehensiveness. There are many ways to make tourists obtain the sense of beauty. Besides attracting the attention of tourists with design of tourism theme projects and central scenic spots, it is also required to attach importance to contents of overall aesthetic value of tourism resources influenced by affiliated culture of tourist attractions. A major problem met in the process of development and utilization of tourism resources in China is that the development of tourism projects is regarded as core content while importance is not attached to the development of connotations of tourist attractions. In design and construction of tourism resources, most investors and developers of tourism resources put all energy into main projects of tourist attractions. However, the development and utilization of tourism resources remain in the extensive utilization mode of one-time investment and continuous consumption. Extensive mode is mainly manifested in two aspects: first, investors and developers of tourism resources have shallow understandings of the development of connotations of tourism resources. Special snacks, characteristic handiwork and civil recreational activities in tourist attractions are decentralized and the workmanship and service of handiwork and recreational activities are coarse, which cannot make tourists have the sense of beauty. Second, investment is inadequate in condition construction. Though the condition of tourism resources cannot improve utilization value of tourism resources, it can improve overall aesthetic value of tourism products. Such extensive mode of development and utilization of tourism resources causes mess in toilet, poor sanitary condition of restaurant, simple and crude infrastructures and poor quality of road in scenic spots, reduces aesthetic value of tourist attractions greatly and increases the probability of complaint about scenic spots, thus shortening their life. Therefore, the scope of development of tourism resources shall be expanded appropriately. It is required to attach importance to main projects of development and strengthen exploitation and planning of local culture. 


\section{Thinking on "aesthetic capacity” of tourism landscape}

Tourism capacity put forward in 1960s regards psychological feelings of tourists as judgment criteria and mainly refers to hold the largest quantity of tourists on the basis of not reducing experience and feeling quality of tourism resources. There are many successful cases of research on tourism capacity. However, theoretical study on tourism capacity cannot keep pace with the development of tourism. It is common that scenic spots are overcrowded in holidays and festivals in China. Such phenomenon is called as blowout in tourism industry. It is difficult to make tourists have the sense of beauty. Scenic spots in China generally have aesthetic capacity severely exceeding the limit. Participation of tourism aesthetics obviously points out that aesthetic subject of tourism resources is relative. Tourists play the role of both audience and actor. Therefore, with the popularization of tourism activities, the study on tourism aesthetic capacity should be regarded as the core research object.

\section{Envisage second-degree aesthetics}

Coordination of second-degree aesthetics is the standard for aesthetic value of tourism products. First-degree aesthetics of tourism originates from professional perspective of tourism industry, while second-degree aesthetics comes from aesthetic psychology of tourists. They have great differences. How to shorten their gap is an important issue of study of tourism resource developers. Therefore, second-degree aesthetics should be put in the first place and tourism resources and products should be transformed according to tourist demands for tourism aesthetics. In the process of development and utilization of tourism resources, it is required to study variation trend of aesthetic psychology and the law of psychological activities of tourists and conduct investigation on tourist market and marketing activities. This does not advocate secularizing and commercializing scenic spots and tourism projects for pleasing tourists blindly. It is proposed to guide aesthetic taste of tourists correctly, pay attention to the development and cultivation of tourism market and close the gap between first-degree aesthetics and second-degree aesthetics.

\section{Development concept of tourism city}

Ecological concept: traditional tourism industry takes the development path of first pollution and then control, which causes serious damage of tourism resources and ecological system. Famous ecologist points out that urban ecological system is a compound artificial ecological system centering on human beings. In the development process of tourism industry, it is required to regard ecology as the first object of protection and prevent ecological system from damage. The orientation of tourism industry should be ecological restaurant, shop and clothing etc.

Characteristic concept: with the development of tourism city, competition in tourism industry becomes fiercer. Therefore, urban tourism should have individuality, fully exploit local characteristics and seek for appropriate tourism resources from human and natural resources so as to find out aesthetic orientation appropriate for city development.

\section{Conclusion}

Tourism aesthetics and development and utilization of tourism resources have close relationship. They are inseparable and supplement each other. Developers and investors of tourism resources must attach importance to tourism aesthetics in development and utilization of tourism resources so as to improve aesthetic value of tourism resources and extend the life of resources.

\section{References}

[1] Cheng Jin. Study on Relationship between Preservation of Cultural Relics and Utilization of Tourism Resources, Technology and Market, 2015,(05):335. 
[2] Li Jing. Study on Development and Utilization of Literary and Artistic Resources in Guanzhong Region, Culture Journal, 2015,(05):136-138.

[3] Wang Lulu. View on Development and Protection of Tourism Resources from Dialectical Relationship between Human and Nature, Business, 2015,(24):103.

[4] Liu Lanlan. Review on Research Literature of Tourism Development Aesthetics, Chizi, 2015,(03):146.

[5] Hu Hongmei. Type Analysis and Development Path of Tourism Resources of Tea Culture in Xinyang, Henan, Fujian Tea, 2016,38(10):131-132.

[6] Zhang Xiaolin, Sun Wei, Liu Lan. Study on Creative Development of Sports Cultural Tourism Resources of Characteristic Villages of Minorities - Based on Investigation and Study on Dehang Miao Village in Western Hunan, Guizhou Ethnic Studies, 2015,(01):156-159.

[7] Sun Guoxue. Thinking on Development of Hongshan Cultural Tourism Resources - Based on Perspective of Mass Cultural Identification, Journal of Chifeng University, 2016,37(11):11-14.

[8] Han Ying, Bai Mei, Feng Wenyong, Li Xiuying et al. Study on Development of Tourism Resources in Wutaishan National Geological Park, Journal of Changchun Normal University, 2015,(10):88-93.

[9] Yin Qun. Study on Tourism Development of Marriage Custom Experience of Bai Nationality Take Zhoucheng, Dali, Yunnan for Example, Economic Research Guide, 2015,(04):247-249.

[10]Wang Zhimin, Li Xiaojie. Study on Tourism Development of Gaozhou Puppet Show from the Perspective of Experience Economy, Theatrical Family, 2016,(16):244-245. 